\title{
La levée du secret médical met en danger la sécurité publique
}

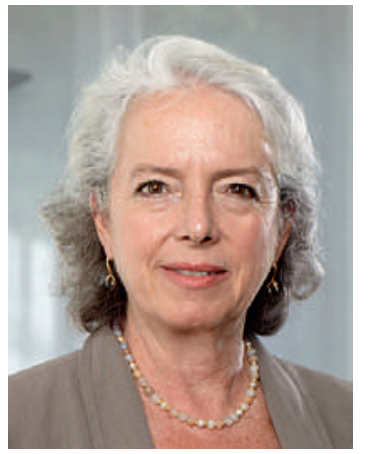

Si les médecins acceptaient de livrer les informations qui sont en leur possession, la population serait-elle mieux protégée contre certains individus réputés dangereux? C'est en tous cas la question qui revient avec insistance sur plusieurs fronts, en Suisse et en Europe, comme une réponse simple au problème sécuritaire. En Suisse, elle se pose concernant les détenus dangereux ou les requérants déboutés. En Europe, c'est en Turquie que la question est brûlante, cette fois sur le front de la contestation politique: les médecins turcs sont mis sous pression pour avoir secouru et soigné des manifestants blessés au cours des manifestations du Parc Gezi de l'année dernière. Ils sont aujourd'hui menacés de lourdes sanctions par les tribunaux du pays, s'ils continuent de refuser de livrer des informations personnelles sur les personnes blessées durant les manifestations. Là aussi, les autorités parlent de sécurité publique [1]!

\section{Une pesée d'intérêts soigneuse permet de dégager des solutions, qui garantissent l'équité des soins mais aussi la sécurité publique.}

Pourtant, le secret médical s'est imposé au fil des siècles comme une mesure indispensable à cette même sécurité publique, et c'est la raison pour laquelle il a été fermement imposé aux professionnels concernés, qui peuvent être lourdement sanctionnés en cas de non-respect. L'article $321 \mathrm{du}$ Code pénal suisse (CPS) prévoit toutefois des exceptions mais qui doivent être inscrites dans une loi fédérale ou cantonale.

Les erreurs qui ont abouti aux meurtres dramatiques de 3 jeunes femmes dans différents cantons par des récidivistes dangereux ne sont pas dues au secret médical, comme le décrit bien le rapport relatif au postulat 11.4072 Amherd de l'Office fédéral de la justice [2]. Les médecins ou thérapeutes en cas d'absolue nécessité peuvent déjà s'appuyer sur l'art. 17 du CPS pour avertir les autorités sans avoir l'accord de leur patient. L'état de nécessité doit se comprendre comme «une situation dans laquelle un danger imminent ne peut être écarté autrement».Cela doit rester un motif exceptionnel de levée du secret médical, au même titre que le consentement du patient est un motif ordinaire de levée du secret.

Dans la pratique, même si le droit n'établit pas une obligation, les médecins pénitentiaires considèrent clairement qu'il est de leur devoir de communiquer. Ils sont bien conscients de leur responsabilité sociale, et d'ailleurs les traitements pour lesquels ils s'engagent visent sur le long terme à une réduction de la dangerosité, afin de permettre une réinsertion du détenu dans la société.

\section{Les erreurs qui ont abouti aux meurtres dramatiques de 3 jeunes femmes par des récidivistes dangereux ne sont pas dues au secret médical.}

Malheureusement, le projet de révision de la loi valaisanne d'application du code pénal (LACP) introduit un «devoir de signalement» à l'article $28 \mathrm{~b}$, en semant plus de confusion et de doutes que d'éclaircissements par rapport au droit fédéral. Or, il faut absolument éviter que les fronts se crispent inutilement. En général, une pesée d'intérêts soigneuse permet de dégager des solutions, qui garantissent l'équité des soins mais aussi la sécurité publique. Une bonne communication entre soignants et autorités est dans les faits possible, à condition de bien définir les rôles de chacun et d'en respecter les limites. Le travail pluridisciplinaire en prison peut fonctionner de façon satisfaisante, en s'appuyant sur différents corps professionnels de santé ou de sécurité, avec l'ajout d'experts indépendants chargés à la demande d'un juge d'évaluer l'évolution d'un prisonnier, et en particulier sa possible dangerosité.

La communication entre médecins et autorité de renvoi répond à la même logique, même si la sécurité publique semble moins directement impactée, puisqu'il s'agit avant tout de protéger un requérant face à d'éventuels risques médicaux liés à un renvoi sous contrainte. Là aussi, la confusion des rôles, les attentes démesurées face aux médecins, amènent à des blocages dommageables, alors qu'une meilleure préparation du renvoi et une répartition des responsabilités de chacun rétablit le dialogue nécessaire.

Malgré leur apparente simplicité, les propositions d'assouplissement du secret médical susmentionnées sont non seulement inaptes à atteindre les buts poursuivis, mais aboutissent à affaiblir notre sécurité. Par conséquent, elles sont rejétées par le corps médical. Ce n'est qu'ensemble qu'on pourra trouver des solutions pour rassurer la population, face à des angoisses sécuritaires tout-à-fait légitimes.

Monique Gauthey, médecin spécialiste, responsable du département Médecins hospitaliers

1 www.wma.net/fr/40news/20archives/2014/2014_33/index. html

2 www.ejpd.admin.ch/dam/data/bj/sicherheit/smv/ dokumentation/ber-po-amherd-f.pdf 